\title{
Use of Lorazepam in Drug-Assisted Interviews: Two Cases of Dissociative Amnesia
}

\author{
Sang-Shin Lee ${ }^{1,2}$, Sinhyung Park ${ }^{1}$ and Si-Sung Park ${ }^{1,2} \otimes$ \\ ${ }^{1}$ Department of Neuropsychiatry, Kosin University Gospel Hospital, Busan, Korea \\ ${ }^{2}$ Department of Neuropsychiatry, Kosin University College of Medicine, Busan, Korea
}

Drug-assisted interviews are useful for psychiatric diagnosis and treatment. However, amobarbital, a typical medication used for this purpose, is associated with elevated risk of respiratory depression. Benzodiazepines are good substitutes for amobarbital, with similar therapeutic effects and fewer complications. Although drug-assisted interviews are not widely used, they may be beneficial for selected patients who do not respond to conventional treatments such as supportive psychotherapy or psychopharmacotherapy. We report two cases of dissociative amnesia that were treated using lorazepam-assisted interviews. The use of lorazepam in drug-assisted interviews is effective and safe for resolving dissociative amnesia.

Psychiatry Investig 2011;8:377-380

Key Words Drug-assisted interview, Lorazepam, Dissociative amnesia.

\section{INTRODUCTION}

Drug-assisted interviews are valuable diagnostic and therapeutic tools in psychiatry.-3 The main indications for drugassisted interviews are conditions such as catatonia, confusion, conversion disorder, factitious disorder, mutism, and psychogenic amnesia. The standard method of drug-assisted interviews, the "Amytal interview" method, requires the use of a sedative, amobarbital, which is a medium-acting barbiturate. ${ }^{2,3}$ However, amobarbital demands careful attention due to the risk of respiratory depression. ${ }^{4}$ Use of this technique is very limited due to the possible side effects of barbiturates and the lack of a specific reversing agent. ${ }^{5}$

Benzodiazepines are a safer class of drug than barbiturates and are less likely to cause respiratory depression. An antagonist, flumazenil, is available. Therefore, benzodiazepines have been suggested as safer pharmacologic alternatives to barbiturates for drug-assisted interviews. ${ }^{6}$ Use of benzodiazepines such as midazolam, diazepam and lorazepam have been re-

Received: April 21, 2011 Revised: July 22, 2011

Accepted: July 25, 2011 Available online: November 3, 2011

$\triangle$ Correspondence: Si-Sung Park, MD, PhD

Department of Neuropsychiatry, Kosin University College of Medicine, 34 Amnam-dong, Seo-gu, Busan 602-703, Korea

Tel: +82-51-990-6638, Fax: +82-51-241-5831, E-mail: ssprk@ns.kosinmed.or.kr

(a) This is an Open Access article distributed under the terms of the Creative Commons Attribution Non-Commercial License (http://creativecommons.org/licenses/bync/3.0) which permits unrestricted non-commercial use, distribution, and reproduction in any medium, provided the original work is properly cited. ported for patients with various mental illnesses. ${ }^{7-9}$ We report the safe and effective use of lorazepam in drug-assisted interviews in two cases of dissociative amnesia.

\section{CASES}

\section{Case 1}

An 18-year-old man was admitted to the psychiatry department with aggressive and violent behavior one day prior to admission. However, he could remember nothing about his behavior or the violent incident. Forty-five days before hospitalization, he had experienced his first dissociative episode. After using a computer for an hour, he suddenly perceived that a photo board was covered with a mass of scribbles that was consisted of abusive language and the names of people whom he hated. Two weeks later, the patient experienced a second episode. While reading a martial arts novel, he noticed that his book was torn. However he was not able to recall what happened. The day before admission, after finishing a test at school, the patient suddenly found himself sitting in a chair in the library on the 2nd floor about 100 meters away from his classroom on the 4th floor. The librarian, a young woman whom he knew from a book club, was bleeding from her head and was grabbing his collar. The police came to investigate. The patient was very embarrassed because he reportedly could not remember what had happened to her.

On admission to the psychiatric unit, the patient was dys- 
phoric and felt guilty. He stated, "I cannot remember anything." Although he described ideas of reference and hearing the screams of monsters, his reality testing were within normal range. No other specific psychopathologies were found. Laboratory examinations and radiological studies of the patient's brain yielded normal results. He denied drinking alcohol or using drugs.

The patient had been raised by his great aunt since the divorce of his parents when he was 4 years old and had not kept in touch with his parents. His great aunt had not been carefully tuned to his emotional or physical development, and he felt that he had been neglected. the patient was shy and introverted and seldom expressed emotion. At 6 months prior to his first amnestic episode, he had contacted his father and decided to live with him, who had remarried, and his father's new wife. However, he reported experiencing conflicts with his stepmother and might have reexperienced the past neglect. We hypothesized that he had repressed aggression derived from unfulfilled wishes for love and it was discharged as symptoms of amnestic syndrome, which may have been precipitated by some traumatic experience.

The patient was diagnosed with "dissociative amnesia" and treated with fluoxetine $20 \mathrm{mg}$. His emotions and mood stabilized within 5-7 hospital days. He attended several sessions of supportive psychotherapy that included reassurance and a nondirective approach in order to assist him in integrating his amnestic memory with associated emotions. We also tried to interpret the transference relation. However, he made no specific advances toward recovering his memories, and was encountering legal problems for the violent behavior toward the librarian. Therefore we decided to use a drug-assisted interview to assist in recovering his memories of the dissociative incident. Informed consent was obtained. Two psychiatrists participated as interviewers, and an anesthesiologist monitored and recorded his clinical state during the interview. The interview was performed according to the protocol that was made up by the authors on the basis of the references (Table 1). ${ }^{7,9,10}$ During the drug-assisted interview, the patient was able to recall memories that precipitated the incident. He stated that he loved the victim, the librarian. The day before this episode, he confessed to her that he loved her, but was rejected. The interview lasted approximately one hour. As soon as the drug-assisted interview ended, the patient fell into a deep sleep. The day after his interview, he was able to recall portions of what he had said during the drug-assisted interview and his actions during his dissociative state. As several days passed, he gradually remembered more about the incident. He also appeared more depressed and reported experiencing anxiety. Oral alprazolam $0.25 \mathrm{mg}$ twice a day was added to his medications. After his depressed mood and anxiety had im-

Table 1. The protocol used for lorazepam-assisted interviews

Preparation

- Informed consent is obtained.

- The patient is placed in a reclining position.

- The patient is maintained on an intravenous drip of $500 \mathrm{cc}$ of $5 \%$ dextrose.

- An emergency kit and pulse oximetry are prepared.

· Lorazepam $10 \mathrm{mg}$ in N/S $300 \mathrm{cc}$ and flumazenil are available.

Procedure

- Pulse oximetry and vital signs are monitored.

- Induction of hypnosis: Lorazepam is slowly administered intravenously at $0.05 \mathrm{mg} / \mathrm{min}$ until the patient shows mild drowsiness and lateral nystagmus.

- Maintenance of hypnosis: During the interview, the administration of lorazepam can be adjusted from $0.05 \mathrm{mg} / \mathrm{min}$ to $0.1 \mathrm{mg} / \mathrm{min}$. The patient is observed for relaxation and sleepiness so that $\mathrm{s} /$ he does not fall asleep and is encouraged to engage with the interview continuously.

- Closing of the interview: After 45 minutes, the rate of lorazepam is decreased to less $0.05 \mathrm{mg} / \mathrm{min}$ and is stopped when 60 minutes have passed.

- The exact amount of lorazepam administered and the administration rate depend on patient response, vital signs and percentage of oxygen saturation.

- Lorazepam is withheld if the oxygen saturation drops below $85 \%$.

Flumazenil $0.1 \mathrm{mg} / \mathrm{mL}$ is immediately injected to reverse oversedation and respiratory depression if they occur.

Termination

- The patient should maintain absolute bed rest for an additional 15-30 minutes after the interview is over and be closely observed for vital signs and oxygen saturation. 
proved, he was discharged in 36 hospital days.

\section{Case 2}

A 17-year-old woman was admitted to the psychiatric department with amnesia. She was in the 3rd degree of high school and majored in playing the trumpet. One day before admission, she was violently attacked and almost kidnapped by a robber on the way home from school, but was rescued by witnesses of the attack. She developed a great deal of anxiety and was unable to remember any events from the time of her high school entrance to the traumatic event. She also was unable to remember how to play the trumpet, an instrument that she had played for the past three years. We performed a thorough medical work-up. There were no abnormal findings to explain her amnesia. We treated her with psychotropics (alprazolam $1.5 \mathrm{mg} /$ day and paroxetine $20 \mathrm{mg} /$ day) and supportive psychotherapy. Her mood stabilized and her anxiety lessened. However, her amnesia persisted. We hypothesized that a lorazepam-induced interview could facilitate release of the emotional tension. Informed content was obtained. We conducted a lorazepam-induced interview according to our protocol (Table 1). During the interview, the patient reported that her parents expected her to enter an elite secondary school after she graduated middle school. However, her academic achievement did not meet her parents' expectations, and she felt guilty. She said she had instead attended a vocational high school. However her parents continuously insisted that she should continue to university. The patient reported that she "desperately did her best" in order to obtain her parents' approval. As part of these efforts, she changed her major to trumpet in pursuit of continuing to university. However she was not able to play the trumpet well enough to enter university. She reported feeling increasing guilt and hostility toward her parents as time went on. With the help of the drugassisted interview, the patient was encouraged to fully express her hostility and guilt toward her parents. After two sessions of drug-assisted interviews she was able to recall almost all episodic and procedural memories that had been dissociated from her consciousness. She was discharged with restored memory in 24 hospital days.

\section{DISCUSSION}

Dissociative amnesia is "an inability to recall important personal information, usually of a traumatic or stressful nature, that is too extensive to be explained by ordinary forgetfulness." ${ }^{11}$ Drug-assisted interviews in psychiatry have been used for 80 years and their usefulness in both diagnostic and therapeutic roles has been explored. ${ }^{2,12}$

We reported two cases of dissociative amnesia. Neither pa- tient responded to conventional supportive psychotherapy or psychopharmacotherapy. In particular, the first case required swift resolution of his selective amnesia due to legal implications. Through lorazepam-assisted interviews, we were able to recall repressed memories with associated emotions in both cases.

Barbiturates are part of the standard protocol for the treatment of dissociative amnesia. ${ }^{2}$ However, due to side effects of respiratory depression and significant interactions with central nervous system drugs, we chose to use a benzodiazepine instead..$^{2-5}$ Lorazepam yields similar results to barbiturates when used for drug-assisted interviews. Thus, we used lorazepam for these cases.

From the perspective of neurocognitive science, functional amnestic patients have state-dependent activity. ${ }^{13}$ The medial temporal and diencephalon memory retrieval mechanism is inhibited when trying to recall traumatic memories in such patients. ${ }^{14}$ In a resting state, mnestic block syndrome is sustained in the form of functional dissociation of the frontotemporal regions through the release of stress hormones. ${ }^{15}$ From a neurobiological perspective, functional amnesia is associated with increased activity of N-Methyl-D-aspartate (NMDA) receptors. ${ }^{16}$ In our two cases, we postulated that lorazepam inhibited aroused prefrontal activity and NMDA receptor activity during the drug-assisted interview.

Although it may not have been severe, the patient in case 1 required further observation for impulsivity and disinhibition during the post-interview period. ${ }^{9}$ The patient also showed mild depression and anxiety after the interview. Thus it is prudent to plan for the provision of support and reassurance in preparation for the interview. If the interview is recorded, it may be helpful to show the recordings to patients if the patient experiences more amnesia during the interview. ${ }^{17}$

In conclusion, the use of lorazepam in drug-assisted interviews is very effective and safe for resolving dissociative amnesia.

\section{REFERENCES}

1. Perry JC, Jacobs D. Overview: clinical applications of the Amytal interview in psychiatric emergency settings. Am J Psychiatry 1982;139:552559.

2. Kavirajan $H$. The amobarbital interview revisited: a review of the literature since 1966. Harv Rev Psychiatry 1999;7:153-165.

3. Fackler SM, Anfinson TJ, Rand JA. Serial sodium Amytal interviews in the clinical setting. Psychosomatics 1997;38:558-564.

4. Ho IK, Harris RA. Mechanism of action of barbiturates. Annu Rev Pharmacol Toxicol 1981;21:83-111.

5. Kwentus JA. Interviewing with intravenous drugs. J Clin Psychiatry 1981;42:432-436.

6. Nishino S, Mignot E, Dement WC. Sedative-hypnotics. In: Schatzberg AF, Nemeroff CB, Editors. The American Psychiatric Press Textbook of Psychopharmacology, 2nd Edition. Washington DC: The American Psychiatric Press, 1998, p.487-500. 
7. Marcum JM. The use of midazolam with pulse oximetry in the drugassisted interview. J Clin Psychiatry 1996;57:111-113.

8. Ballew L, Morgan Y, Lippmann S. Intravenous diazepam for dissociative disorder: memory lost and found. Psychosomatics 2003;44:346347.

9. Ilechukwu ST, Henry T. Amytal interview using intravenous lorazepam in a patient with dissociative fugue. Gen Hosp Psychiatry 2006;28:544545 .

10. Labbate LA, Arana GW, Ballenger JC. Barbiturates and Similarly Acting Substances. In: Sadock BJ, Sadock VA, Editors. Kaplan \& Sadock's Comprehensive Textbook of Psychiatry, 7th Edition. Philadelphia: Lippincott Williams \& Wilkins, 2000, p.2312.

11. American Psychiatric Association. American Psychiatric Association Diagnostic and Statistical Manual of Mental Disorders: Fourth Edition Text Revision (DSM-IV-TR). Washington DC: American Psychiatric Association; 2000.
12. Coons PM. The dissociative disorders. Rarely considered and underdiagnosed. Psychiatr Clin North Am 1998;21:637-648.

13. Bell V, Oakley DA, Halligan PW, Deeley Q. Dissociation in hysteria and hypnosis: evidence from cognitive neuroscience. J Neurol Neurosurg Psychiatry 2011;82:332-339.

14. Kopelman MD. Disorders of memory. Brain 2002;125:2152-2190.

15. Markowitsch HJ. Psychogenic amnesia. Neuroimage 2003;20 (Suppl 1): S132-S138.

16. Loewenstein RJ, Putnam FW. Dissociative disorders. In: Sadock BJ, Sadock VA, Editors. Kaplan \& Sadock's Comprehensive Textbook of Psychiatry, 8th Edition. Philadelphia: Lippincott Williams \& Wilkins, 2005, p.1852-1853.

17. Bradley RH, Zonia CL, Caputo SJ. The amobarbital sodium interview in conversion disorders: use of video feedback in therapy. J Am Osteopath Assoc 1995;95:122-125. 